\title{
Clinical observations on the use of new anti- VEGF drug, conbercept, in age-related macular degeneration therapy: a meta-analysis
}

\author{
Chunmei Cui \\ Hong Lu \\ Department of Ophthalmology, Beijing \\ Chao-Yang Hospital, Beijing, China
}

This article was published in the following Dove Press journal: Clinical Interventions in Aging
Correspondence: Hong Lu Department of Ophthalmology, Beijing Chao-Yang Hospital, the Worker's Stadium Road No 8, Chaoyang District, Beijing 100020, China

Tel +86 I37 0I 220319

Email honglu_2016@163.com
Purpose: Conbercept is a new anti-vascular endothelial growth factor (VEGF) drug approved for the treatment of age-related macular degeneration (AMD). Although this novel drug has been widely used in clinic, unlike other anti-VEGF drugs, validation and consensus on its method of clinical application and clinical safety have not yet been achieved.

Methods: Relevant literature was searched on PubMed, Web of Science, China National Knowledge Internet, and Wanfang Data. Stata 12.0 was used for data analysis. Random- and fixedeffect models were employed to evaluate heterogeneity. Best-corrected visual acuity (BCVA) and central retinal thickness (CRT) were utilized to measure the improvement of AMD patients. Results: In this study, we analyzed conbercept administration and compared its application with other control clinical methods for AMD treatment. Ranibizumab, triamcinolone, and traditional transpupillary thermotherapy (TTT) were administered in the control group. No differences were found in the BCVA and CRT improvement between the groups treated with conbercept and ranibizumab. However, the conbercept group had a lower serum VEGF level. After 3 months of treatment, conbercept led to a more significant BCVA and CRT improvement than triamcinolone. A more considerable BCVA improvement was observed in the group treated with conbercept than in the group treated with TTT. Moreover, even 6 months after the treatment, the effect of conbercept on CRT improvement was still more pronounced than that of TTT.

Conclusion: In AMD patients, conbercept exerts considerably more positive effects on the long-term BCVA and CRT improvement than triamcinolone and TTT. The serum VEGF level in the conbercept group was lower than that in the ranibizumab group.

Keywords: AMD, VEGF, conbercept, BCVA, CRT

\section{Introduction}

AMD is a progressive degenerative disease of the retina, whose incidence increases with age and it can cause severe visual impairment and even blindness in some serious cases. ${ }^{1}$ The condition mostly occurs in middle-aged patients, at an approximate age of 50 years ${ }^{1,2}$ and is one of the three major causes of blindness in the world.,.$^{2,3}$ Predictive estimates indicate that by 2020 AMD prevalence will affect more than 3 million people in the USA alone. Along with the changing social structure of an aging population, this unfavorable trend will be observed not only in the USA but also globally. AMD is considered to become an increasingly important, globally prevalent social issue in the future.

Two main types of AMD exist based on its clinical manifestations: atrophy type (dry or non-exudative) and exudation type (wet). ${ }^{4}$ The early stages of AMD are usually asymptomatic or characterized by minor symptoms. In general, drusen and pigmentary 
changes are present within the macula. ${ }^{5,6}$ Due to the phagocytic activities of the retinal pigment epithelial cells, the availability of discs containing visual pigment molecules is reduced, which causes malignant development of AMD. ${ }^{7,8}$ As a result, the remaining undissociated membrane discs are retained in the basal cell mycelia and excreted to extracellular space. Eventually, the residual bodies of the membrane discs are deposited on the Bruch's membrane, forming a drusen, which is a small yellowish macular lesion or speck. These fundus pathological changes are obvious due to the specific properties of the structure and function of the macula. A variety of pathological changes can lead to macular degeneration, and thus drusens are also found in elderly with normal vision. During disease progression, the Bruch's membrane is disrupted and subsequently locally dissolved. ${ }^{9-11}$ Through the rupture of the Bruch's membrane, the choriocapillaris penetrates under the retinal pigmented epithelium and retinal neurosensory layer, and $\mathrm{CNV}$ is formed, which is one of the hallmarks of AMD. ${ }^{2}$ Without treatment, $\mathrm{CNV}$ can cause destruction of the macular structures, including the retinal pigment epithelium cells and the photoreceptors, resulting in the development of a disciform scar and associated severe central visual loss. ${ }^{9,12}$ The resulting structural abnormalities in the new blood vessel wall facilitate the occurrence of vascular leakage and bleeding, which subsequently trigger a series of secondary pathological changes.

Although the etiological and pathophysiological mechanisms of AMD are not yet elucidated, an extensive abnormal ocular neovascularization has been recognized as the main reason leading to blindness of AMD patients. VEGF promotes abnormal vascular proliferation in AMD patients. ${ }^{13-16}$ VEGF-A belongs to the VEGF family, which includes six isoforms: VEGF-A, PIGF1, PIGF2, VEGF-B, VEGF-C, and VEGF-D. Each of these isoforms can bind to a specific combination of three vascular endothelial growth factor receptors of VEGFR-1, -2, and -3. ${ }^{17,18}$ Currently, anti-VEGF drugs have been widely used for AMD treatment, achieving promising clinical results. At present, three anti-VEGF agents have been approved by the US FDA for the treatment of AMD: pegaptanib, ${ }^{19}$ ranibizumab,${ }^{20}$ and the newly registered aflibercept. ${ }^{21}$

Recently, conbercept was approved by the China Food and Drug Administration for the treatment of neovascular AMD in China. ${ }^{2,22}$ This common name of China's first new "biological" classes of drugs with entirely independent intellectual property rights that has been internationally recognized. Conbercept is a genetically engineered homodimeric protein that inhibits the activity of VEGF-family proteins, and is used for the treatment of wet AMD. ${ }^{23,24}$ Similar to VEGF Trap-Eye, conbercept (also named KH902;23,24 Chengdu Kanghong Biotech Co., Ltd., Sichuan, China) is a recombinant, soluble, VEGF-receptor protein that was designed as a receptor decoy composed of the second Ig domain of VEGFR-1, and the third and fourth Ig domains of VEGFR-2, and the constant region $(\mathrm{Fc})$ of the human IgG1. Previous studies have demonstrated that domain 4 of VEGF receptor 2 is essential for receptor dimerization and enhances the rate of VEGF association to the receptor. ${ }^{25}$ Preclinical examinations have shown that conbercept binds to and neutralizes VEGF-A and all its isoforms, which results in a binding affinity that is higher than that of ranibizumab. ${ }^{24,26}$ Moreover, conbercept shows a higher PlGF-binding activity compared with ranibizumab.

Conbercept has been used in clinic practice throughout China. However, at present, most of the data concerning the administration of conbercept in China are provided by clinical trials with non-standardized design, and, unlike other anti-VEGF drugs, consensus has still not been reached on its clinical safety and efficacy, dose, and optimal methods for clinical application.

Therefore, there is an urgent need to apply these findings in clinical practice to provide better treatment for AMD on the global scale. Thus, we performed this meta-analysis of RCTs to investigate the effects of the application of conbercept in AMD treatment.

\section{Methods}

\section{Literature search}

An electronic literature search was conducted on PubMed, Web of Science, EMBASE, Cochrane library databases, China National Knowledge Internet, and Wanfang Data. The search keywords and terms used were combined as follows: "Conbercept, KH902, FP3" and/or "Ranibizumab, Triamcinolone, traditional transpupillary thermotherapy", and “Agerelated macular degeneration, AMD, macular degeneration, Macular disease". The search results were limited to randomized clinical trials. We searched by keywords and read the title, abstract, and full text to select the English and Chinese articles. The final search was carried out on October 2016. As it is a meta-analysis, ethical approval is not required.

\section{Inclusion and exclusion criteria}

The inclusion criteria were as follows: 1) Study design: randomized clinical controlled trials involving AMD patients; 2) patients: enrollment of middle-aged and elderly patients with AMD in the studies; 3 ) therapeutic methods: setup of a control treatment in all examinations; and 4) data: ability to quantify all the data of results of all articles. 
The following exclusion criteria were utilized: 1) no control group in the clinical trials (including self-, pre-, and post-control); 2) patients suffering from another macular disease; 3) experimental data not quantified in the publication; and 4) case reports, editorials, meeting abstracts, animal, and cell experimental studies.

\section{Outcome measures}

The following indicators and definitions were used to evaluate the outcomes of the trials: 1) eyesight: Early Treatment Diabetic Retinopathy Study (ETDRS) charts were use to obtain the mean changes of BCVA. Further, the data were recorded as dichotomous and continuous variables. For the dichotomous variable data, obviously effective and effective transformation were considered to represent a satisfactory clinical effect (total effective rate $=$ obviously effective + effective). Obviously effective: visual acuity improved by two or more lines after treatment; effective: visual acuity improved by one line or visual acuity improved from light perception to 0.1 ; ineffective: vision without any improvement after treatment. 2) CRT: determined by using ocular coherence tomography. The scanning mode was selected by horizontal and vertical direction linear scan through fovea and quantitative measurement; and 3) the concentration of VEGF (ng/L) was determined in the serum extract according to the inclusion criteria.

\section{Data extraction}

Two reviewers independently extracted data for each article included in the study. If inconsistencies were encountered, they were resolved by discussion and analysis. The basic information of the experimental and control groups of patients was extracted from each article (Table 1). We performed post-treatment assessments of the data for BCVA

Table I Characteristics of the I 3 studies

\begin{tabular}{|c|c|c|c|c|c|c|c|c|c|c|c|}
\hline \multirow[t]{2}{*}{ Name } & \multirow{2}{*}{$\begin{array}{l}\text { Published } \\
\text { year }\end{array}$} & \multirow{2}{*}{$\begin{array}{l}\text { Collection } \\
\text { period }\end{array}$} & \multirow{2}{*}{$\begin{array}{l}\text { Treatment } \\
\text { mode }\end{array}$} & \multirow[t]{2}{*}{ BCVA } & \multicolumn{3}{|c|}{ Experiment group } & \multicolumn{4}{|c|}{ Control group } \\
\hline & & & & & E-eye & E-dose & Manufacturer & CT & C-eye & C-dose & Manufacturer \\
\hline Han et $\mathrm{al}^{38}$ & 2015 & $\begin{array}{l}\text { Feb } 2014 \text { to } \\
\text { Jun } 2014\end{array}$ & I time & $\begin{array}{l}\text { Standard } \\
\text { eye chart }\end{array}$ & 36 & $0.1 \mathrm{~mL}$ & Kanghong & Tri & 36 & $0.1 \mathrm{~mL}$ & JIDA \\
\hline $\begin{array}{l}\text { Zhu and } \\
\text { Liu }^{33}\end{array}$ & 2015 & $\begin{array}{l}\text { May } 2013 \text { to } \\
\text { April } 2014\end{array}$ & $\begin{array}{l}\mathrm{I} W ; 6 \mathrm{M} \\
\mathrm{I}\end{array}$ & $\begin{array}{l}\text { Visual } \\
\text { acuity }\end{array}$ & 35 & $0.1 \mathrm{~mL}$ & NR & Tri & 35 & $0.1 \mathrm{~mL}$ & NR \\
\hline $\operatorname{Ren}^{34}$ & 2016 & $\begin{array}{l}\text { June } 2013 \text { to } \\
\text { June } 2015\end{array}$ & $\begin{array}{l}\text { I/M; } \\
\text { Continuously } \\
\text { for } 3 M\end{array}$ & $\begin{array}{l}\text { Effective } \\
\text { rate }\end{array}$ & 40 & $0.5 \mathrm{mg}$ & NR & Tri & 40 & $0.1 \mathrm{~mL}$ & NR \\
\hline $\begin{array}{l}\text { Dong } \\
\text { et } \mathrm{al}^{35}\end{array}$ & 2016 & $\begin{array}{l}\text { Jan } 2012 \text { to } \\
\text { Jan } 2015\end{array}$ & $\begin{array}{l}\text { I/M; } \\
\text { Continuously } \\
\text { for } 3 \mathrm{M}\end{array}$ & $\begin{array}{l}\text { Snellen } \\
\text { Eye Chart }\end{array}$ & 40 & $\begin{array}{l}0.05 \mathrm{~mL} \\
10 \mathrm{mg} / \mathrm{mL}\end{array}$ & Kanghong & Tri & 40 & $0.1 \mathrm{~mL}$ & $\begin{array}{l}\text { Bristol- } \\
\text { Myers }\end{array}$ \\
\hline He et $\mathrm{al}^{36}$ & 2015 & $\begin{array}{l}\text { March } 2014 \text { to } \\
\text { March } 2015\end{array}$ & $\begin{array}{l}\text { I/M; } \\
\text { Continuously } \\
\text { for } 3 \mathrm{M}\end{array}$ & $\begin{array}{l}\text { Standard } \\
\text { eye chart }\end{array}$ & 30 & $0.1 \mathrm{~mL}$ & NR & Tri & 30 & $0.1 \mathrm{~mL}$ & NR \\
\hline Song et $\mathrm{al}^{37}$ & 2015 & $\begin{array}{l}\text { June } 2014 \text { to } \\
\text { August } 2015\end{array}$ & I time & $\begin{array}{l}\text { Central } \\
\text { vision }\end{array}$ & 48 & $\begin{array}{l}0.5 \mathrm{mg} \\
0.05 \mathrm{~mL}\end{array}$ & Kanghong & Tri & 44 & $\begin{array}{l}0.5 \mathrm{mg} \\
0.05 \mathrm{~mL}\end{array}$ & XIANJU \\
\hline Liu et $\mathrm{al}^{29}$ & 2015 & $\begin{array}{l}\text { March } 2014 \text { to } \\
\text { March } 2015\end{array}$ & $\begin{array}{l}\text { I/M; } \\
\text { Continuously } \\
\text { for } 3 \mathrm{M}\end{array}$ & $\begin{array}{l}\text { Visual } \\
\text { acuity }\end{array}$ & 30 & $1.5 \mathrm{mg}$ & Kanghong & Ran & 30 & $0.05 \mathrm{~mL}$ & $\begin{array}{l}\text { Novartis } \\
\text { Pharma }\end{array}$ \\
\hline Niu et $\mathrm{al}^{30}$ & 2016 & $\begin{array}{l}\text { June } 2014 \text { to } \\
\text { June } 2015\end{array}$ & $\begin{array}{l}\text { I W; I M; } \\
3 \mathrm{M}\end{array}$ & $\begin{array}{l}\text { Standard } \\
\text { eye chart }\end{array}$ & 20 & $0.1 \mathrm{~mL}$ & NR & Ran & 20 & $0.1 \mathrm{~mL}$ & NR \\
\hline $\begin{array}{l}\text { Zhao and } \\
\text { Bai }^{31}\end{array}$ & 2015 & $\begin{array}{l}\text { April } 2013 \text { to } \\
\text { May } 2014\end{array}$ & $\begin{array}{l}\mathrm{I} / \mathrm{M} \text {; } \\
\text { Continuously } \\
\text { for } 3 \mathrm{M}\end{array}$ & $\begin{array}{l}\text { Standard } \\
\text { eye chart }\end{array}$ & 30 & $0.05 \mathrm{~mL}$ & NR & Ran & 31 & $0.05 \mathrm{~mL}$ & NR \\
\hline Jin et $\mathrm{al}^{32}$ & 2016 & 2016 & $\begin{array}{l}\text { I W; } \\
\text { I M; } 3 \text { M }\end{array}$ & NR & 18 & $\begin{array}{l}0.5 \mathrm{mg} \\
0.05 \mathrm{~mL}\end{array}$ & NR & Ran & 10 & $\begin{array}{l}0.5 \mathrm{mg} \\
0.05 \mathrm{~mL}\end{array}$ & NR \\
\hline Zhang ${ }^{39}$ & 2015 & $2013-2014$ & $\begin{array}{l}\text { I/M; } \\
\text { Continuously } \\
\text { for } 3 \mathrm{M}\end{array}$ & $\begin{array}{l}\text { Effective } \\
\text { rate }\end{array}$ & 49 & $0.5 \mathrm{mg}$ & Kanghong & TTT & 49 & $\begin{array}{l}\text { Infrared } \\
\text { radiation }\end{array}$ & NR \\
\hline Wang $^{40}$ & 2015 & $\begin{array}{l}\text { April } 2013 \text { to } \\
\text { April } 2014\end{array}$ & $\begin{array}{l}\mathrm{I} / \mathrm{M} \\
\text { Continuously } \\
\text { for } 3 \mathrm{M}\end{array}$ & $\begin{array}{l}\text { Effective } \\
\text { rate }\end{array}$ & 30 & $0.5 \mathrm{mg}$ & NR & TTT & 30 & $\begin{array}{l}\text { Infrared } \\
\text { radiation }\end{array}$ & NR \\
\hline Liu et $\mathrm{al}^{4 !}$ & 2016 & $\begin{array}{l}\text { Jan } 2015 \text { to } \\
\text { Dec } 2015\end{array}$ & $\begin{array}{l}\text { I/M; } \\
\text { Continuously } \\
\text { for } 3 \mathrm{M}\end{array}$ & $\begin{array}{l}\text { Effective } \\
\text { rate }\end{array}$ & 56 & $0.5 \mathrm{mg}$ & Kanghong & TTT & 56 & $\begin{array}{l}\text { Infrared } \\
\text { radiation }\end{array}$ & NR \\
\hline
\end{tabular}

Abbreviations: BCVA, best corrected visual acuity; E-eye, number of experimental group eyes; E-dose, experimental group eye dose; CT, the control group therapy; C-eye, number of control group eyes; C-dose, control group eye dose; W, week; M, month; Y, years; NR, not refer; Tri, triamcinolone; Ran, ranibizumab; TTT, traditional transpupillary thermotherapy. 
and CRT to impute a change-from-baseline SD using a correlation coefficient.

\section{Quality assessment}

We used the "Cochrane Handbook for Systematic Reviews of Interventions" to assess the risk of bias to evaluate the quality of the trials included. Six parameters concerning the quality of the RCTs were observed in the trials: 1) sequence generation, 2) allocation concealment, 3) patient blinding, 4) personnel and outcome assessors, 5) management of incomplete outcome data, and 6) selective outcome reporting. There were three possible choices for each parameter. "Yes" represented a low risk of bias, "no" indicated a high risk of bias, and "unclear" denoted unclear or unknown risk of bias.

\section{Statistical analysis}

Stata version 12.0 (Stata Corp, College Station, TX, USA) was used for the meta-analysis. Risk ratios were used in the comparisons of dichotomous variables data. Weighted mean differences and standard mean differences were employed in the comparisons of continuous variables data. All statistical analyses were conducted with $95 \%$ confidence intervals. We utilized $I^{2}$ to evaluate the heterogeneity among studies. Heterogeneity was considered to be low when $I^{2} \leq 50 \%$ in dichotomous and continuous variables, and the data were analyzed by using the fixed-effects model. If $I^{2}>50 \%$, we accepted that the differences across studies were heterogeneous, and the random-effects model was employed for the data analysis. As baseline continuous variable data, we used those of the experimental group (E) and the control group (C) established before the treatment (baseline mean $1_{E, C}, S D 1_{E, C}$ ), whereas the posttreatment ones were utilized as final data (final mean $2_{E, C}, S D 2_{E, C}$ ). To eliminate the deviation caused by the difference of baseline $\mathrm{SD}$, mean $3_{\mathrm{E}, \mathrm{C}}$ and $\mathrm{SD}_{3 \mathrm{E}, \mathrm{C}}$ were used to the following formula as change mean $\pm \mathrm{SD}$. The following formula was used to calculate the missing SD values for changes from baseline: 27,28

$$
\begin{aligned}
& \operatorname{Mean}_{\mathrm{E}, \mathrm{C}}=\operatorname{Mean}_{\mathrm{E}, \mathrm{C}}-\mathrm{Mean}_{\mathrm{E}, \mathrm{C}} \\
& \mathrm{SD} 3_{\mathrm{E}, \mathrm{C}}=\sqrt[2]{\mathrm{SD} 1_{\mathrm{E}, \mathrm{C}}{ }^{2}+\mathrm{SD} 2_{\mathrm{E}, \mathrm{C}}{ }^{2}-\left(2 * \mathrm{Corr} * \mathrm{SD} 1_{\mathrm{E}, \mathrm{C}} * \mathrm{SD} 2_{\mathrm{E}, \mathrm{C}}\right)}
\end{aligned}
$$

where Corr is the coefficient of correlation between the experimental and control groups. If the value of Corr was not possible to calculate for all the data, the statistics point of view is usually the default of 0.4 or 0.5 . In this study, we adopted a value of Corr $=0.4$, and by using the method described earlier, we obtained the change-from-baseline SD for the experimental and control groups.

\section{Results}

\section{Selection and characteristics of the studies}

Initially, a total of 556 potentially relevant articles were identified by the literature search. Then, 480 articles were excluded because they did not meet the inclusion criteria. After reading the title and the abstract of each of the remaining 76 articles, we excluded another 52 articles from our analysis. Further, we read the full text of the remaining 24 articles and excluded 11 articles that did not adhere strictly to our inclusion criteria. Finally, 13 articles remained, among which four investigated the effects of ranibizumab, ${ }^{29-32}$ six triamcinolone, ${ }^{33-38}$ and three TTT. ${ }^{39-41}$ Fundus examination of the parameters data analysis was carried out to find the differences between the conbercept treatment group and each of others control group. The trial selection process is presented in Figure 1, and the summarized basic information and the details of the 13 articles are shown in Table 1. All studies were RCTs conducted in clinical settings. No special emphasis was placed on drug manufacturers, although their recommended dosage was generally utilized in the trials.

\section{Conbercept and ranibizumab}

The 1-month treatment of AMD patients with conbercept did not lead to a significant improvement in their BCVA

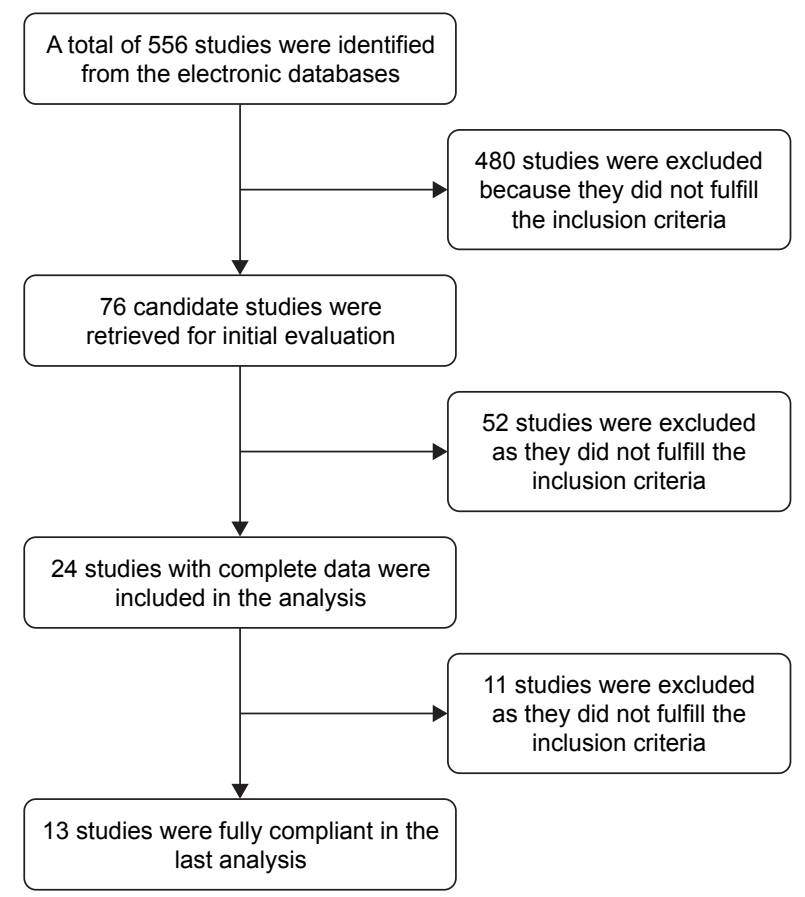

Figure I Cochrane risk of bias of included studies ( $\mathrm{n}=13$ studies). 
as compared with the respective values obtained after the therapy with ranibizumab for the same period of time (Figure 2A; $Z=1.03, P=0.301 ; I^{2}=95 \%, P=0.000$ ). ${ }^{29,30}$ After a 3-month treatment period, we obtained the same result for the level of CRT improvement in AMD patients (Figure 2B; $Z=0.02, P=0.988 ; I^{2}=49.8 \%, P=0.136$; Table 2) ${ }^{29-31}$

In addition, two articles reported different levels of VEGF after 1 month of treatment. ${ }^{29,32}$ Conbercept reduced VEGF serum levels more significantly than ranibizumab (Figure 2C; $\left.Z=3.54, P=0.000 ; I^{2}=0.0 \%, P=0.715\right)$.

\section{Conbercept and triamcinolone}

After 3 months of treatment, a significant improvement was observed for BCVA in patients treated with conbercept compared with those treated with triamcinolone (3-month continuous variables: ${ }^{35,36,38} Z=1.98, P=0.048 ; I^{2}=79.2 \%$, $P=0.008$; 3-month dichotomous variables: ${ }^{34,35} Z=2.76$, $P=0.006 ; I^{2}=0 \%, P=0.748$; Figures 3 and 4$)$. However, there was no difference between the experimental group and the control group after 1 month of treatment (1-month continuous variables: ${ }^{35,36,38} Z=1.43, P=0.151 ; I^{2}=91.7 \%, P=0.000$; 1 -month dichotomous variables: ${ }^{35,37} Z=0.89, P=0.71$; $I^{2}=89.8 \%, P=0.002$; Figures 3 and 4). The continuous and dichotomous variables obtained exhibited the same trend for BCVA improvement in the conbercept- and triamcinolonetreated groups after 1 and 3 months of treatment. The results concerning BCVA improvement obtained after 3-month treatment were better than those obtained after 1-month treatment $\left(Z=2.57, P=0.010 ; I^{2}=87.3 \%, P=0.00\right.$; Figures 3 and 4$){ }^{35,36,38}$

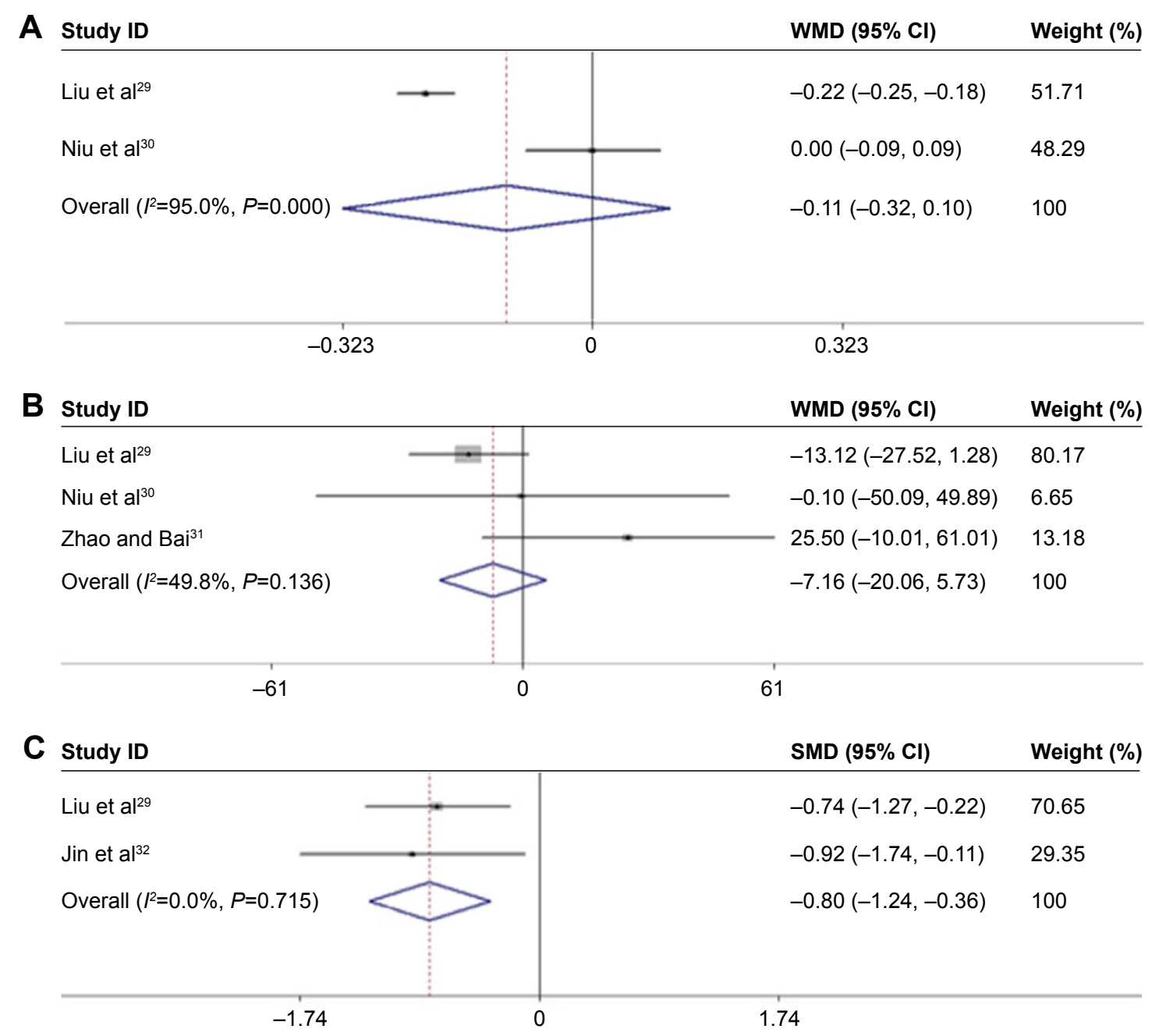

Figure 2 Flowchart of the literature review and study selection process. (A) The BCVA values obtained after I-month treatment of conbercept compared with ranibizumab in AMD patients; (B) the level of CRT after 3-month treatment of conbercept compared with ranibizumab in AMD patients; (C) VEGF serum levels obtained after I month of treatment of conbercept compared with ranibizumab in AMD patients.

Note: Weights are from random-effects analysis.

Abbreviations: BCVA, best-corrected visual acuity; AMD, age-related macular degeneration; CRT, central retinal thickness; VEGF, anti-vascular endothelial growth factor; SMD, standard mean differences; WMD, weighted mean difference. 
Table 2 Statistical analysis of the results

\begin{tabular}{|c|c|c|c|c|c|c|c|c|c|c|}
\hline $\begin{array}{l}\text { Detection } \\
\text { index }\end{array}$ & $\begin{array}{l}\text { Control } \\
\text { group }\end{array}$ & M & $\begin{array}{l}\text { Data } \\
\text { type }\end{array}$ & $\begin{array}{l}\text { Number } \\
\text { of studies }\end{array}$ & $\begin{array}{l}\text { Number } \\
\text { of eyes }\end{array}$ & $\begin{array}{l}\text { RR/ } \\
\text { WMD }\end{array}$ & $95 \% \mathrm{Cl}$ & $\begin{array}{l}\text { Heterogeneity } \\
\text { (\%) }\end{array}$ & $\mathbf{Z}$ & $P$-value \\
\hline \multirow{8}{*}{$\begin{array}{l}\text { BCVA } \\
\text { (logMAR+ } \\
\text { effective) }\end{array}$} & Ran & 1 & Con & 2 & $\mathrm{E}: 50, \mathrm{C}: 50$ & -0.11 & $(-0.32)-(0.10)$ & $P^{2}=95 \%, P=0.000$ & 1.03 & 0.301 \\
\hline & \multirow[t]{4}{*}{ Tri } & \multirow[t]{2}{*}{ I } & Dic & 2 & $\mathrm{E}: 88, \mathrm{C}: 92$ & 1.28 & $0.75-2.17$ & $P^{2}=89.8 \%, P=0.002$ & 0.89 & 0.371 \\
\hline & & & Con & 3 & E:106, C:106 & 0.06 & $(-0.02)-(0.13)$ & $P^{2}=91.7 \%, P=0.000$ & 1.43 & 0.151 \\
\hline & & \multirow[t]{2}{*}{3} & Dic & 2 & $E: 80, C: 80$ & 1.21 & $1.06-1.38$ & $P^{2}=0.0 \%, P=0.748$ & 2.76 & $0.006 *$ \\
\hline & & & Con & 3 & E:106, C:106 & 0.09 & $0.0-0.18$ & $P^{2}=79.2 \%, P=0.008$ & 1.98 & $0.048^{*}$ \\
\hline & \multirow[t]{3}{*}{ TTT } & 1 & Dic & 3 & E:135, C:135 & 1.12 & $1.02-1.22$ & $P^{2}=53.91 \%, P=0.114$ & 2.37 & $0.018^{*}$ \\
\hline & & 3 & Dic & 3 & $\mathrm{E}: 135, \mathrm{C}: 135$ & 1.23 & $1.11-1.36$ & $P^{2}=11.1 \%, P=0.325$ & 4.07 & $0.000 *$ \\
\hline & & 6 & Dic & 3 & E:135, C:135 & 1.98 & $1.65-2.39$ & $P^{2}=0.0 \%, P=0.787$ & 7.21 & $0.000 *$ \\
\hline CRT & $\operatorname{Ran}$ & 3 & Con & 3 & $E: 80, C: 81$ & 0.20 & $(-25.02)-(25.4 \mathrm{I})$ & $P^{2}=49.8 \%, P=0.136$ & 0.02 & 0.988 \\
\hline \multirow[t]{5}{*}{$(\mu \mathrm{m})$} & \multirow[t]{2}{*}{ Tri } & 1 & Con & 3 & E:106, C:106 & -87.23 & $(-167.56)-(-6.90)$ & $P^{2}=86.2 \%, P=0.00 \mathrm{I}$ & 2.13 & 0.033 \\
\hline & & 3 & Con & 3 & E:106, C:106 & -50.74 & $(-93.42)-(-8.07)$ & $P^{2}=62.6 \%, P=0.069$ & 2.33 & $0.020 *$ \\
\hline & \multirow[t]{3}{*}{ TTT } & 1 & Con & 2 & $\mathrm{E}: 79, \mathrm{C}: 79$ & -12.72 & $(-60.94)-(35.50)$ & $P^{2}=0.0 \%, P=0.906$ & 0.52 & 0.605 \\
\hline & & 3 & Con & 2 & $\mathrm{E}: 79, \mathrm{C}: 79$ & -19.42 & $(-67.27)-(28.44)$ & $P^{2}=0.0 \%, P=0.858$ & 0.80 & 0.426 \\
\hline & & 6 & Con & 2 & E:79, C:79 & -72.92 & $(-123.91)-(-22.33)$ & $P^{2}=0.0 \%, P=0.880$ & 2.83 & $0.005^{*}$ \\
\hline VEGF (ng/L) & Ran & I & Con & 2 & $\mathrm{E}: 48, \mathrm{C}: 40$ & -0.80 & $(-1.24)-(-0.36)$ & $P^{2}=0.0 \%, P=0.715$ & 3.54 & $0.000 *$ \\
\hline
\end{tabular}

Note: *Statistically significant.

Abbreviations: BCVA, best-corrected visual acuity; CRT, central retinal thickness; VEGF, vascular endothelial growth factor; Ran, ranibizumab; Tri, triamcinolone; TTT, traditional transpupillary thermotherapy; Con, continuous; Dic, dichotomous; E, experiment group; C, control group; WMD, weighted mean difference.

Based on the continuous variable data obtained, we found that CRT improved more significantly in the conbercepttreated group than in the triamcinolone-treated group after 1 month $^{35,36,38}$ and 3 months ${ }^{33,35,36}$ of treatment (Figure 5).

\section{Comparative effects of conbercept and TTT}

Analysis of dichotomous outcome data for three of the studies $^{39-41}$ showed that the improvement in patients' BCVA

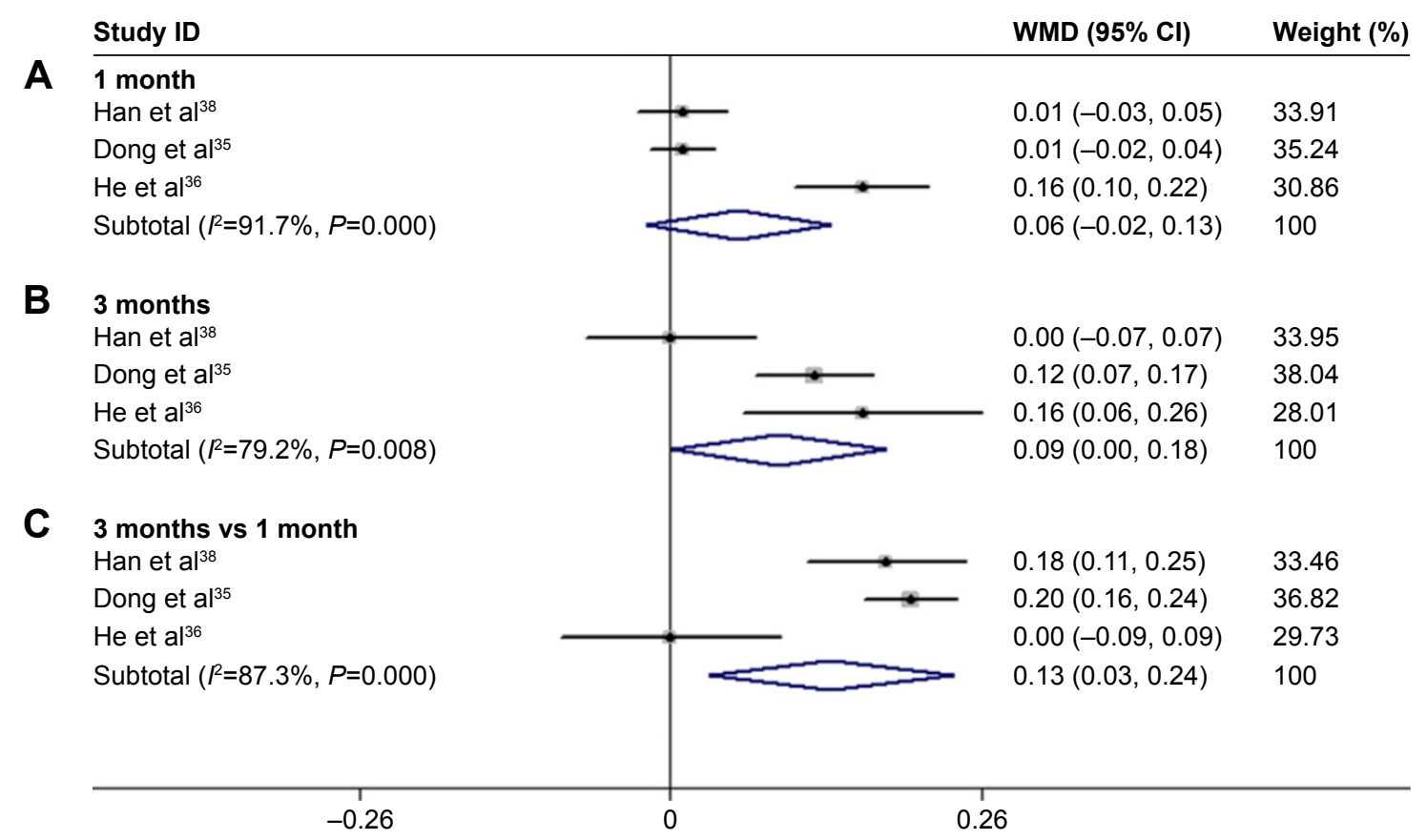

Figure 3 Comparison of the effect between conbercept and ranibizumab treatments on BCVA and CRT improvement in AMD therapy. (A) Forest plots of conbercept and ranibizumab for BCVA improvement in patients with AMD after I month of treatment. (B) BCVA improvement after 3 months of treatment with conbercept and ranibizumab. (C) Serum levels of VEGF. Fixed- and random-effects models were used for the analysis. Diamonds and horizontal lines correspond to the study-specific weighted mean differences (WMD), standard mean differences (SMD), and 95\% Cl, respectively. WMD and SMD were used in the determination of continuous variables. Note: Weights are from random-effects analysis.

Abbreviations: BCVA, best-corrected visual acuity; AMD, age-related macular degeneration; CRT, central retinal thickness; VEGF, anti-vascular endothelial growth factor; $\mathrm{Cl}$, confidence interval. 


\begin{tabular}{|c|c|c|c|}
\hline Study ID & & $\operatorname{RR}(95 \% \mathrm{Cl})$ & Weight (\%) \\
\hline \multicolumn{4}{|l|}{1 month } \\
\hline Dong et $\mathrm{al}^{35}$ & 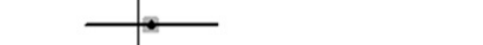 & $1.03(0.88,1.20)$ & 52.98 \\
\hline Song et $\mathrm{a}^{\mid 37}$ & & $1.63(1.20,2.20)$ & 47.02 \\
\hline Subtotal $\left(I^{2}=89.8 \%, P=0.002\right)$ & 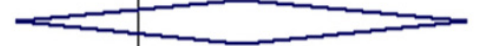 & $1.28(0.75,2.17)$ & 100 \\
\hline \multicolumn{4}{|l|}{3 months } \\
\hline $\operatorname{Ren}^{34}$ & & $1.24(1.00,1.54)$ & 38.16 \\
\hline Dong et $\mathrm{a}^{35}$ & $\longrightarrow$ & $1.19(1.00,1.41)$ & 61.84 \\
\hline Subtotal $\left(I^{2}=0.0 \%, P=0.748\right)$ & & $1.21(1.06,1.38)$ & 100 \\
\hline
\end{tabular}

Figure 4 Forest plots of continuous variables of the effect on BCVA improvement in AMD patients after I and 3 months of treatment with conbercept vs triamcinolone. The random-effects model was used for the analysis. Horizontal lines are mean $95 \% \mathrm{Cl}$.

Abbreviations: BCVA, best-corrected visual acuity; AMD, age-related macular degeneration; $\mathrm{Cl}$, confidence interval.

after 1, 3, and 6 months of conbercept treatment was significantly higher than those achieved after TTT treatment (1-month treatment: $Z=2.37, P=0.018 ; I^{2}=53.91 \%, P=0.114$; 3-month treatment: $Z=4.07, P=0.000 ; I^{2}=11.1 \%, P=0.325$; 6-month treatment $Z=7.21, P=0.000 ; I^{2}=0.0 \%, P=0.787$; Figure 6).
The continuous variables of three studies indicated that after 6 months of treatment with conbercept, patients' CRTs were significantly improved compared to those achieved after the treatment with TTT $\left(Z=2.83, P=0.005 ; I^{2}=0.0 \%, P=0.880\right)$. There was no statistically significant difference between the experimental group and control group after 1 month and

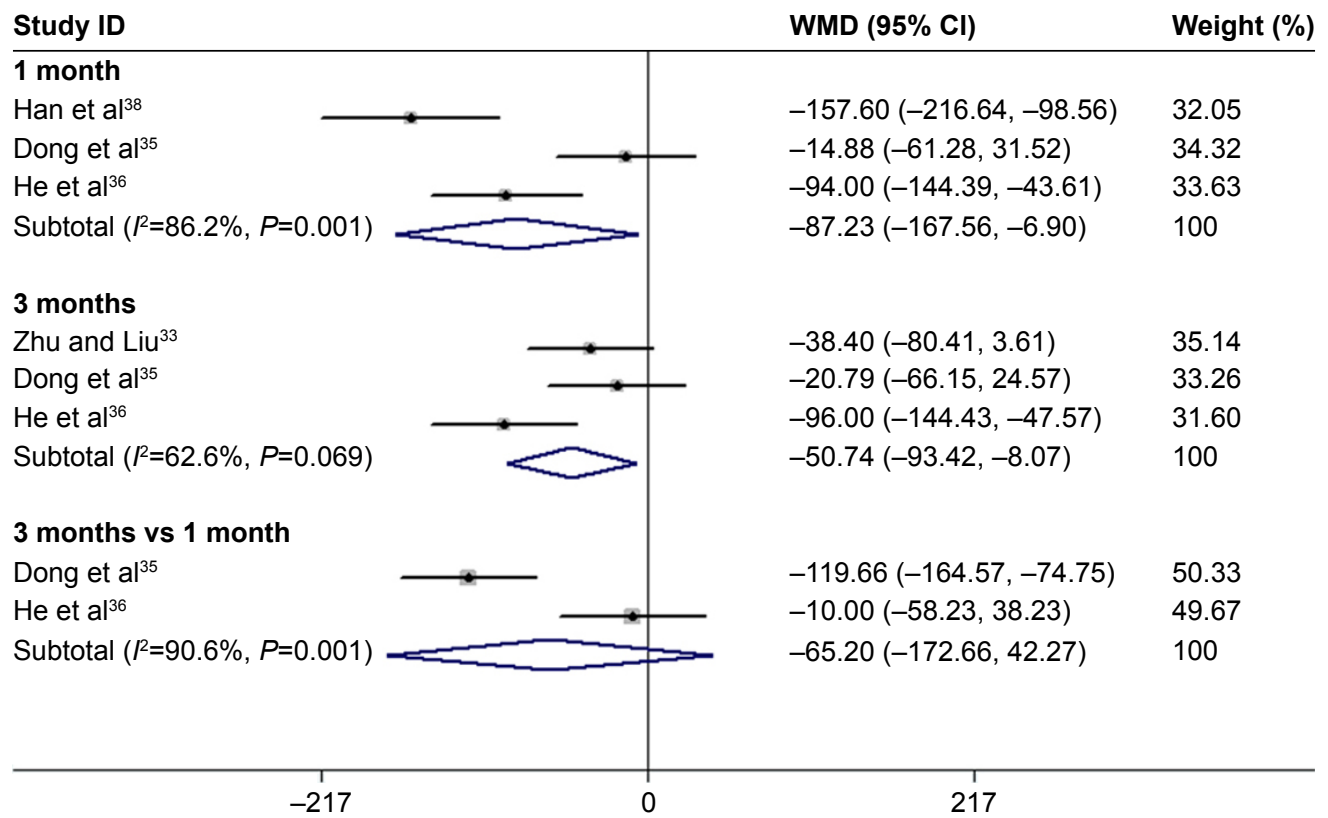

Figure 5 Forest plots of dichotomous variables of BCVA improvement after I and 3 months of treatment with conbercept and triamcinolone in AMD patients. The random-effects model was used for the analysis. The risk ratios (RR) were employed to compare dichotomous variables. Weights are from random-effects analysis. Horizontal lines are mean $95 \% \mathrm{Cl}$.

Abbreviations: BCVA, best-corrected visual acuity; AMD, age-related macular degeneration; $\mathrm{Cl}$, confidence interval. 


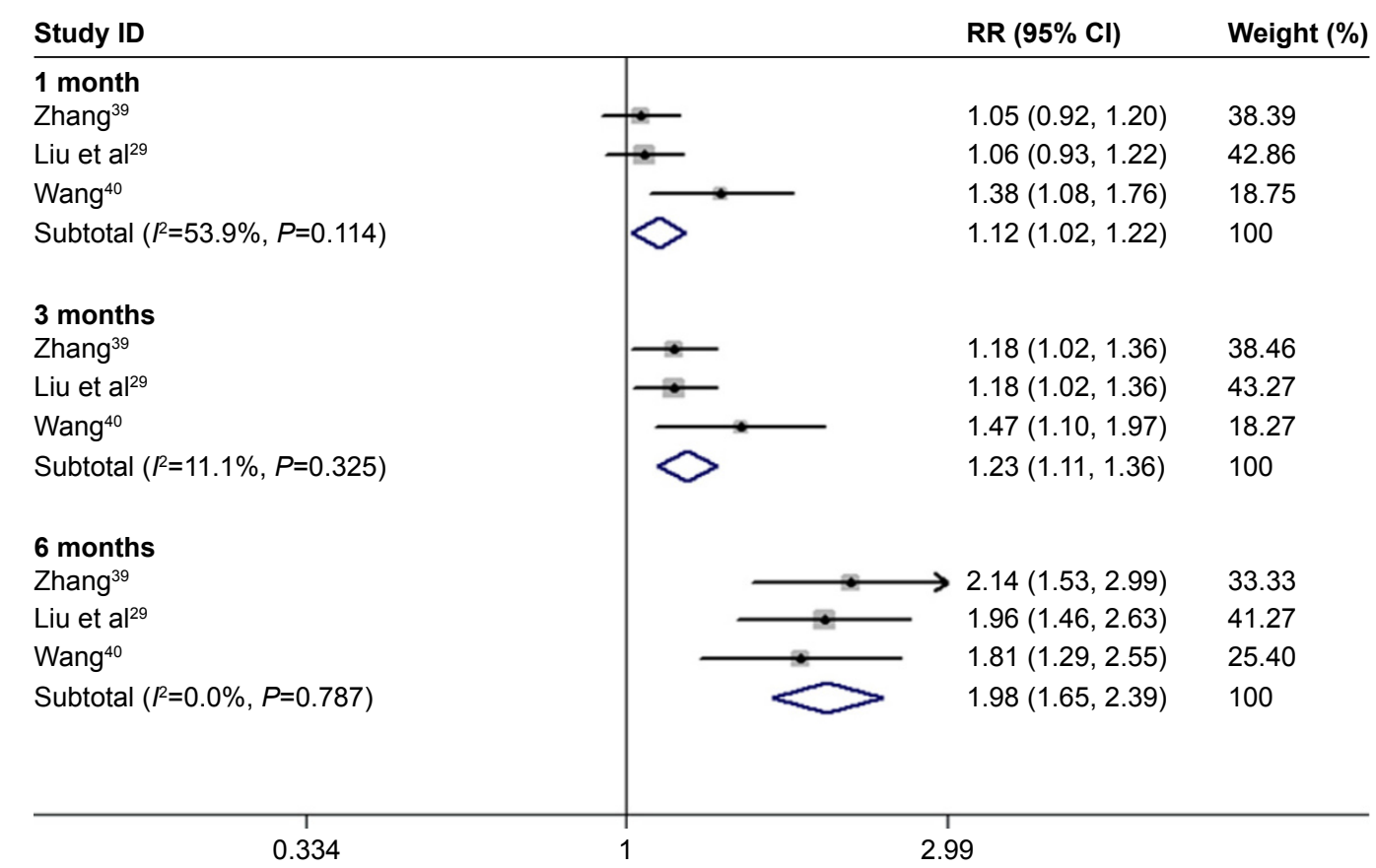

Figure 6 Forest plots of continuous variables of CRT improvement in AMD patients after I and 3 months of treatment with conbercept vs triamcinolone. The random-effects model was used for the analysis.

Abbreviations: CRT, central retinal thickness; AMD, age-related macular degeneration; RR, risk ratio; Cl, confidence interval.

3 months of treatment (1-month treatment: $Z=0.52, P=0.605 ; \quad$ analyses. Due to the difference in the treatment methods, $I^{2}=0.000, P=0.906$; 3-month treatment: $Z=0.80, P=0.426$; the number of patients, medication time and drug times, $I^{2}=0.000, P=0.858$; Figure 7)..$^{39,40}$

dosage and surgical operations contributed to heterogeneity.

To explore the potential sources of heterogeneity in To eliminate this heterogeneity, we used strict inclusion the present meta-analysis, we conducted several subgroup criteria and excluded the obviously low-quality articles.

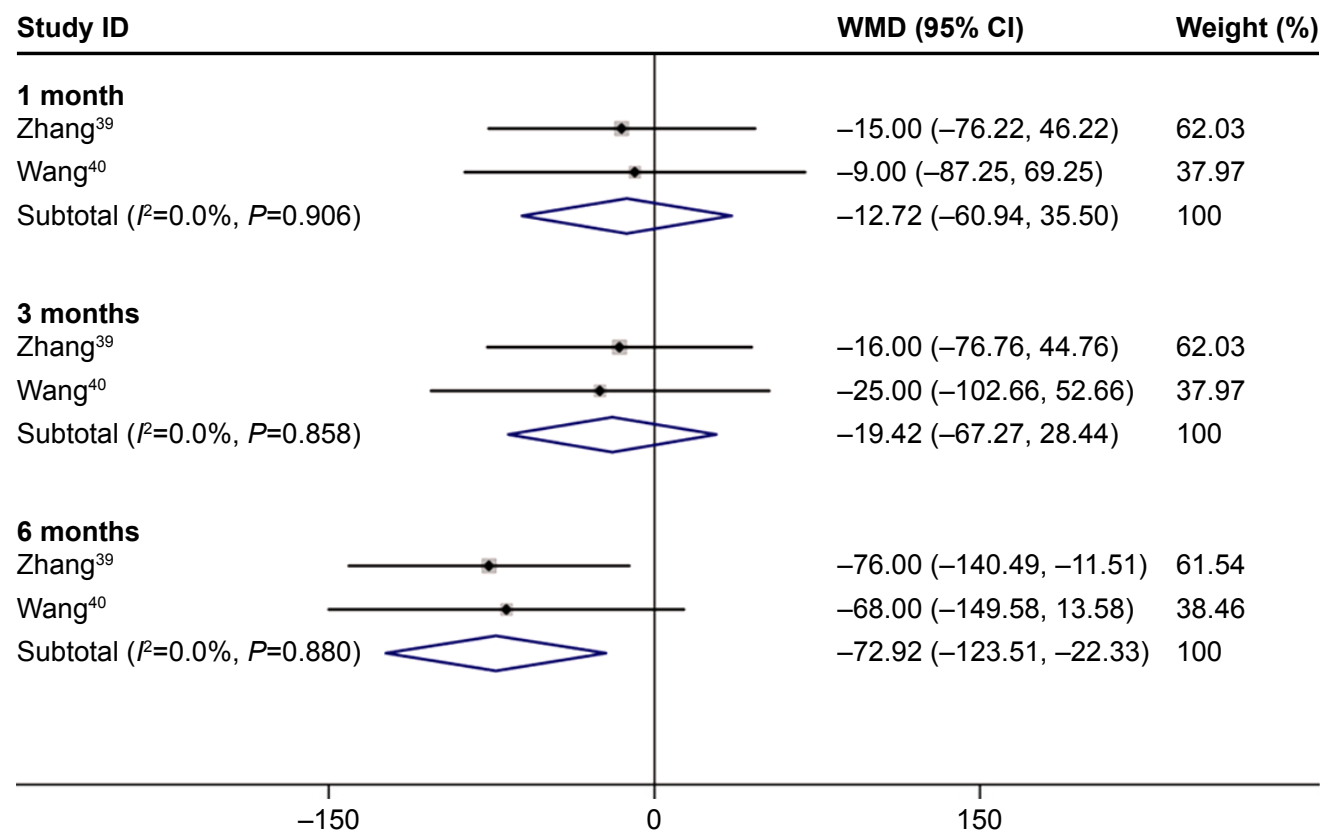

Figure 7 Forest plots of dichotomous variables of the effect on BCVA improvement after I, 3, and 6 months of treatment with conbercept compared with that achieved after traditional transpupillary thermotherapy (TTT) in AMD patients. The fixed-effects model was used for the analysis.

Abbreviations: BCVA, best-corrected visual acuity; AMD, age-related macular degeneration; Cl, confidence interval. 
A

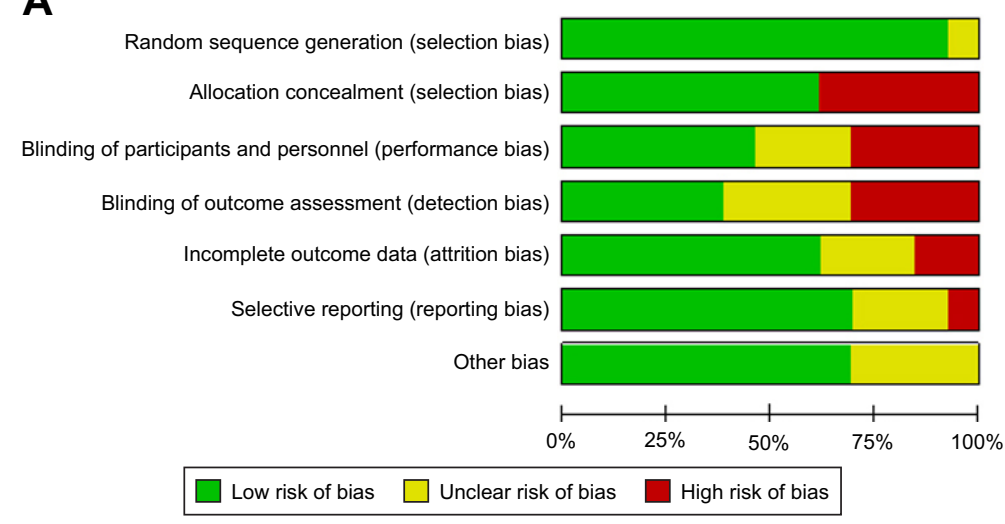

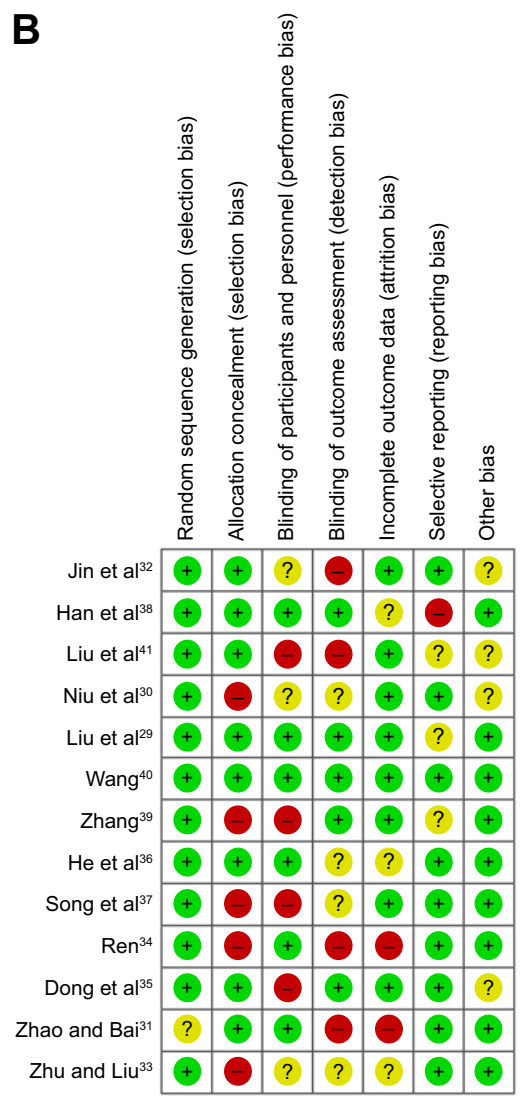

Figure 8 Risk of bias graph. (A) Review authors' judgments about each "Risk of bias" item presented as percentages across all included studies; (B) the detailed risk of bias values for each article.

We also used the fixed-effects model to exclude the results of no or low heterogeneity, whereas in cases of high heterogeneity of results, we employed the random-effect model.

\section{Publication bias}

Since there were few articles in each of the three control groups, this would inevitably have led to a certain degree of publication bias. There might have also been unpublished literature. All of these causes can contribute to publication bias. The instructions in the Cochrane Handbook for Systematic Reviews of Interventions were followed to assess the risk of bias and to evaluate the quality of the trials included (Figure 8). ${ }^{42}$

\section{Discussion}

Conbercept, a genetically engineered homodimeric protein that functions by blocking VEGF-family proteins, is used for the treatment of AMD. ${ }^{2}$ It is China's first biological class of new drugs with fully independent intellectual property rights and an internationally recognized common name included in WHO's database. Currently, it is widely used in the clinical treatment of AMD. However, the data concerning its clinical application have not been systematically sorted out. Subsequently, by conducting the present meta-analysis, we aimed at selecting, collecting, and assessing the studies on the clinical applications of conbercept.

Only two inhibitors of VEGF (pegaptanib and ranibizumab) approved by the US FDA for the treatment of exudative AMD and under commercial development since 2008 were available before the development of conbercept. ${ }^{25}$ However, both of them have to be injected into patients every 4 to 6 weeks to maintain a therapeutic level of VEGF inhibition. In an attempt to eliminate these limitations, Zhang et $\mathrm{a}^{43}$ developed this improved VEGF inhibitor that exerts more potent effects and can be administered less frequently. Conbercept has a high affinity for all VEGF isoforms and PlGF. It is a recombinant fusion protein that is composed of human VEGF receptor 1 domain 2 and human VEGF receptor 2 domains 3 and 4, and the Fc portion of human IgG1. ${ }^{23,24,43}$ Conbercept was also named KH902 or FP3 before its application in clinical practice. ${ }^{44}{ }^{46} \mathrm{It}$ is produced by Chinese hamster ovary cell lines. ${ }^{43}$ The researchers who developed conbercept aimed to demonstrate its efficacy in the treatment of lesions in a monkey model of a laser-induced 
lesion, CNV. The results showed that the CNV leakage was obviously smaller than it was before the injection; moreover, there was no leakage at the end of the observation (after the injection was administered). In the next (Phase I) study, the authors selected 28 patients who suffered from CNV resulting from exudative $\mathrm{AMD}^{24}$ and applied different doses (from 0.05 to $3 \mathrm{mg}$ ) of the drug. Follow-up examinations were performed on post-injection days $1,3,5,7,14,28$, and 42 . The treatment with conbercept was found to exert adequate clinical effects on BCVA, CRT, and CNV in this Phase I study. Later, Li et $\mathrm{al}^{23}$ conducted a twelve-month randomized Phase II study on the efficacy and safety of conbercept in the therapy of neovascular AMD. Patients were randomly divided into two groups with an equal number, in which two different doses of the drug $(0.5$ and $2.0 \mathrm{mg})$ were administered for three consecutive months. After the 3-month treatment, BCVA was the same as or better than those observed after 12 months of treatment in both the conbercept dose groups of neovascular AMD patients. Importantly, repeated intravitreal injections of conbercept were well tolerated in AMD patients. At present, as the clinical, randomized, double-masked, and controlled-dose experiment has been successfully completed, conbercept is widely used for the treatment of AMD patients.

In the present study, we compared the effects obtained after the treatment of patients with AMD with conbercept with those obtained after the application of other therapeutic methods. Ranibizumab was the first VEGF inhibitor to be approved by the US FDA for exudative AMD treatment. Nevertheless, the results of some studies evidenced that the 1-day injection with ranibizumab had a minimal effect on the serum or plasma VEGF level, which reached initial therapeutic level soon afterward. Similarly, the obtained systemic VEGF level was sustained over 1 month in the serum or plasma of AMD patients treated with bevacizumab. ${ }^{47-50}$ There were no significant differences in the improvement of BCVA and CRT between the group treated with conbercept and that treated with ranibizumab. However, the 1-month treatment with conbercept lowered the serum VEGF level more considerably than that with bevacizumab, and the difference was statistically significant.

Triamcinolone is a long-acting cortical hormone produced by the adrenal gland that is artificially synthesized and widely used in the treatment of AMD, macular edema, and uveitis. ${ }^{51}$ The findings of our study indicate that after 3 months of treatment with conbercept, appreciable BCVA improvement was achieved $(P<0.05)$. Compared with triamcinolone, conbercept can significantly reduce the thickness of CRT. Thus, we speculate that conbercept is likely to have a better long-term effect in the treatment of AMD patients than triamcinolone.

TTT is employed in the treatment of eye diseases. For example, semiconductor infrared laser irradiation with a wavelength of $810 \mathrm{~nm}$ is usually applied for therapy of macular lesions. And it achieved the treatment effect treatment of AMD patients by to increase the local retina temperature. ${ }^{52,53}$

In our meta-analysis, we found that the application of conbercept improved BCVA in AMD patients. The positive effects of the 6-month treatment with conbercept on CRT thickness were more pronounced than those achieved by TTT. This finding suggests that the treatment of AMD patients with conbercept is superior to that with TTT. In particular, the effect was more obvious after the long-term treatment with the drug.

Recent research shows that the combination of PDT and anti-VEGF drugs is superior to using either alone. In an earlier study, triple therapy was investigated that was designed for the treatment of neovascular AMD consisting of PDT, an anti-VEGF drug (intravitreal bevacizumab), and intravitreal triamcinolone. ${ }^{51}$ It seems that the application of the triple therapy showed a better effect than the single therapy administered for a short period of time. This result provides a new approach to the application of conbercept in the treatment of AMD. We established that in some of the studies included in our meta-analysis, conbercept exerted a more pronounced effect in the therapy of AMD than the control treatments. Therefore, conbercept can be considered as an anti-VEGF drug that deserves wide popularization for AMD treatment.

\section{Conclusion}

In conclusion, conbercept exerts more positive effects on the long-term BCVA improvement in AMD patients than triamcinolone and TTT. Our findings indicate that conbercept has a therapeutic effect that is identical to that of ranibizumab, but conbercept reduces the concentration of serum VEGF during the period of treatment. In addition, conbercept has a therapeutic effect that is identical to that of ranibizumab but is superior to the one of TTT in the long-term treatment of AMD patients. Nonetheless, long-term data on the effectiveness and safety of this treatment method are required to confirm these findings.

\section{Abbreviations}

VEGF, anti-vascular endothelial growth factor; AMD, agerelated macular degeneration; BCVA, best-corrected visual 
acuity; CRT, central retinal thickness; TTT, traditional transpupillary thermotherapy; $\mathrm{CNV}$, choroidal neovascularization; PlGF, placenta growth factor; PlGF1, placental growth factor 1; PlGF2, placental growth factor 2; SD, standard deviation; PDT, photodynamic therapy; RCT, randomized controlled trial; US FDA, the United States Food and Drug Administration.

\section{Disclosure}

The authors report no conflicts of interest in this work.

\section{References}

1. Nguyen TT, Guymer R. Conbercept (kh-902) for the treatment of neovascular age-related macular degeneration. Expert Rev Clin Pharmacol. 2015;8(5):541-548.

2. Wu Z, Zhou P, Li X, et al. Structural characterization of a recombinant fusion protein by instrumental analysis and molecular modeling. PLoS One. 2013;8(3):e57642-e57642.

3. Yang S, Zhao J, Sun X. Resistance to anti-VEGF therapy in neovascular age-related macular degeneration: a comprehensive review. Drug Des Devel Ther. 2016;10:1857-1867.

4. Dan HB, Young TA. Age-related macular degeneration: a practical approach to a challenging disease. J Am Geriatr Soc. 2006;54(7): 1130-1135.

5. Tl VDS, Mooy CM, de Bruijn WC, et al. Histologic features of the early stages of age-related macular degeneration. A statistical analysis. Ophthalmology. 1992;99(2):278-286.

6. Tl VDS, Mooy CM, de Bruijn WC, et al. Early stages of age-related macular degeneration: an immunofluorescence and electron microscopy study. Br J Ophthalmol. 1993;77(10):657-661.

7. Ambati J, Fowler B. Mechanisms of age-related macular degeneration. Ophthalmol Clin North Am. 2012;75(1):26-39.

8. Nowak JZ. Age-related macular degeneration (AMD): pathogenesis and therapy. Pharmacol Rep. 2006;58(3):353-363.

9. Bhutto I, Lutty G. Understanding age-related macular degeneration (AMD): relationships between the photoreceptor/retinal pigment epithelium/Bruch's membrane/choriocapillaris complex. Mol Aspects Med. 2012;33(4):295-317.

10. Killingsworth MC, Sarks JP, Sarks SH. Macrophages related to Bruch's membrane in age-related macular degeneration. Eye. 1990; 4(1):613-621.

11. Priore LVD, Tezel TH, Kaplan HJ. Maculoplasty for age-related macular degeneration: reengineering Bruch's membrane and the human macula. Prog Retin Eye Res. 2006;25(6):539-562.

12. Mettu PS, Wielgus AR, Ong SS, et al. Retinal pigment epithelium response to oxidant injury in the pathogenesis of early age-related macular degeneration. Mol Aspects Med. 2012;33(4):376-398.

13. Ciulla TA, Rosenfeld PJ. Anti-vascular endothelial growth factor therapy for neovascular ocular diseases other than age-related macular degeneration. Curr Opin Ophthalmol. 2009;20(3):166-174.

14. Ozkiris A. Anti-VEGF agents for age-related macular degeneration. Expert Opin Ther Pat. 2010;20(1):103-118.

15. Long S. Anti-VEGF therapy in age-related macular degeneration Journal of Nihon University Medical Association. 2015;74:134-136.

16. Brown DM, Regillo CD. Anti-VEGF agents in the treatment of neovascular age-related macular degeneration: applying clinical trial results to the treatment of everyday patients. Am J Ophthalmol. 2007;144(4): 627-637.

17. Platania CBM, Paola LD, Leggio GM, et al. Molecular features of interaction between VEGFA and anti-angiogenic drugs used in retinal diseases: a computational approach. Front Pharmacol. 2015; 6:248.
18. Li XR, Liu JP. Recognition of anti-VEGF therapy base on the mechanism of VEGF in wet age-related macular degeneration. Chinese J Exp Ophthalmol. 2012;30(4):289-292.

19. Gragoudas ES, Adamis AP, Cunningham ET Jr, et al. Pegaptanib for neovascular age-related macular degeneration. Am J Ophthalmol. 2004; 139(4):761-762.

20. Rosenfeld PJ, Brown DM, Heier JS, et al. Ranibizumab for neovascular age-related macular degeneration. $N$ Engl J Med. 2006;355(14): 1419-1431.

21. Heier JS, Brown DM, Chong V, et al. Intravitreal aflibercept (VEAGF trap-eye) in wet age-related macular degeneration. Ophthalmology. 2012;119(12):2537-2548.

22. Lu X, Sun X. Profile of conbercept in the treatment of neovascular age-related macular degeneration. Drug Des Devel Ther. 2015(9): 2311-2320

23. Li X, Xu G, Wang Y, et al. Safety and efficacy of conbercept in neovascular age-related macular degeneration: results from a 12-month randomized phase 2 study: AURORA study. Ophthalmology. 2014;121(9): $1740-1747$.

24. Ming Z, Zhang J, Mi Y, et al. A phase 1 study of kh902, a vascular endothelial growth factor receptor decoy, for exudative age-related macular degeneration. Ophthalmology. 2010;118(4):672-678.

25. Zhang M, Yu D, Yang C, et al. The pharmacology study of a new recombinant human VEGF receptor-fc fusion protein on experimental choroidal neovascularization. Pharm Res. 2008;26(1):204-210.

26. Zhao JL, Liang SQ, Fu W, et al. The lim domain protein fhllc interacts with tight junction protein zo-1 contributing to the epithelialmesenchymal transition (emt) of a breast adenocarcinoma cell line. Gene. 2014;542(2):182-189.

27. Follmann D, Elliott P, Suh I, et al. Variance imputation for overviews of clinical trials with continuous response. J Clin Epidemiol. 1992;45(7): 769-773.

28. Gal D. A mouth-watering prospect: salivation to material reward. J Consum Res. 2012;38(6):1022-1029.

29. Liu R, Liu CM, Li N, et al. Effect of conbercept ophthalmic injection on peripheral blood vascular endothelial growth factor, intraocular pressure and visual acuity in patients with age related macular degeneration. Chinese J Biochem Pharm. 2015;35(8):104-106.

30. Niu JY, Jin Ling, Liu XH, et al. Comparison of efficacy between ranibizumab and conbercept for wet-related macular degeneration. Guangxi Med J. 2016;38(5).

31. Zhao YZ, Bai HN. Comparison of efficacy between ranibizumab and conbercept for neovascularage-ralated macular degeneration. World Latest Medicine Information. 2015;(57).

32. Jin $\mathrm{E}, \mathrm{Bai} \mathrm{Y}$, Luo L, et al. Serum levels of vascular endothelial growth factor before and after intravitreal injection of ranibizumab or conbercept for neovascular age-related macular degeneration. Retina. 2016; 37(5):971-977.

33. Zhu ZL, Liu YX. Clinical effect of conbercept to improve visual acuity of patients with wet age-related macular degeneration. Int J Ophthalmol. 2015;(11):1881-1883.

34. Ren Y. Clinical effect of conbercept to improve wet age-related macular degeneration. Chinese Journal of Medical Device. 2016;29(6).

35. Dong YX, Guan XR, Han WT, et al. Clinical observation of conbercept combined with triamcinolone acetonide in treatment of exudative age-related macular degeneration. Drugs Clin. 2016;31(3): $358-362$.

36. He XT, Wang DL, Zhang H, et al. Clinical study of conbercept intravitreal injection for the treatment of wet age-related macular degeneration. Int J Ophthalmol. 2015;(9):1603-1605.

37. Song YM, Lv PS, Suo LJ. Comparision of intravitreal injection of conbercept and triamcinolone for the treatment of wet age-macular degeneration. The Second Forum on the Exchange of Clinical Acute and Critical. 2015.

38. Han J, Wang L, Liu WS, et al. Effects of conbercept intravitreal Injection on visual acuity of diabetic retinopathy. Chinese General Practice. 2015;18(5):502-506. 
39. Zhang X. Clinical observation on conbercept ophthalmic injection for treating age-related macular degeneration in 49 cases. China Pharmaceuticals. 2015;(12):21-23.

40. Wang XX. Clinical observation on conbercept ophthalmic injection for treating age-related macular degeneration. Maternal and Child World. $2015 ;(24)$.

41. Liu J, Song CP, Gao B. Clinical observation on conbercept injection for treating age-related macular degeneration. J Health Care Guide. 2016; (17):18-18.

42. Higgins JP, Green S. Cochrane handbook for systematic reviews of interventions. Naunyn-Schmiedebergs Archiv für experimentelle Pathologie und Pharmakologie. 2009;2011(14):S38.

43. Zhang M, Zhang J, Yan M, et al. Recombinant anti-vascular endothelial growth factor fusion protein efficiently suppresses choridal neovasularization in monkeys. Mol Vis. 2008;14(4):37-49.

44. Wang H, Shi J, Wang Q, et al. Assessment of the pre-clinical immunogenicity of a new VEGF receptor Fc-fusion protein FP3 with ELISA and BIACORE. Cancer Immunol Immunother. 2010;59(2):239-246.

45. Jin K, He K, Fei T, et al. Fp3: a novel VEGF blocker with antiangiogenic effects in vitro and antitumour effects in vivo. Clin Transl Oncol. 2011;13(12):878-884.

46. Yu DC, Lee JS, Yoo JY, et al. Soluble vascular endothelial growth factor decoy receptor FP3 exerts potent antiangiogenic effects. Mol Ther. 2012;20(5):938-947.

47. Wang X, Sawada T, Sawada O, et al. Serum and plasma vascular endothelial growth factor concentrations before and after intravitreal injection of aflibercept or ranibizumab for age-related macular degeneration. Am J Ophthalmol. 2014;158(4):738-744.
48. Hoerster R, Muether P, Dahlke C, et al. Serum concentrations of vascular endothelial growth factor in an infant treated with ranibizumab for retinopathy of prematurity. Acta Ophthalmol. 2012;91(1):e74-e75.

49. Sozen-Delil FI, Cekic O, Haklar G. Vitreous and serum VEGF levels after intravitreal injection of bevacizumab, ranibizumab and triamcinolone acetonide in patients with proliferative diabetic retinopathy. Acta Opthalmol. 2016;94.

50. Wu WC, Shih CP, Lien R, et al. Serum vascular endothelial growth factor after bevacizumab or ranibizumab treatment for retinopathy of prematurity. Retina. 2017;37(4):694-701.

51. Yip PP, Woo CF, Tang HH, et al. Triple therapy for neovascular age-related macular degeneration using single-session photodynamic therapy combined with intravitreal bevacizumab and triamcinolone. Br J Ophthal. 2009;93(6):754-758.

52. Algvere PV, Libert C, Lindgärde G, et al. Transpupillary thermotherapy of predominantly occult choroidal neovascularization in age-related macular degeneration with 12 months follow-up. Acta Ophthalmol Scand. 2003;81(2):110-117.

53. Reichel E, Berrocal AM, Ip M, et al. Transpupillary thermotherapy of occult subfoveal choroidal neovascularization in patients with age-related macular degeneration. Ophthalmology. 1999;106(10):1908-1914.
Clinical Interventions in Aging

\section{Publish your work in this journal}

Clinical Interventions in Aging is an international, peer-reviewed journal focusing on evidence-based reports on the value or lack thereof of treatments intended to prevent or delay the onset of maladaptive correlates of aging in human beings. This journal is indexed on PubMed Central, MedLine,

\section{Dovepress}

CAS, Scopus and the Elsevier Bibliographic databases. The manuscript management system is completely online and includes a very quick and fair peer-review system, which is all easy to use. Visit http://www.dovepress. com/testimonials.php to read real quotes from published authors. 